\title{
A Simple Levulinate-based Ratiometric Fluorescent Probe for Sulfite with a Large Emission Shift
}

\author{
Caiyun LiU, Huifang Wu, Wen YANG, and Xiaoling ZhANG ${ }^{* \dagger}$ \\ Key Laboratory of Cluster Science of Ministry of Education, Beijing Key Laboratory of Photoelectronic/ \\ Electrophotonic Conversion Materials, School of Chemistry, Beijing Institute of Technology, Beijing 100081, \\ P. R. China
}

\begin{abstract}
A simple 4-hydroxynaphthalimide-derived colorimetric and ratiometric fluorescent probe (1) containing a receptor of levulinate moiety was designed and synthesized to monitor sulfite. Probe $\mathbf{1}$ could quantificationally detect sulfite by a ratiometric fluorescence spectroscopy method with high selectivity and sensitivity. Specially, probe $\mathbf{1}$ exhibited a $100 \mathrm{~nm}$ red-shifted absorption spectrum along with the color changes from colorless to yellow, and $103 \mathrm{~nm}$ red-shifted emission spectra upon the addition of sulfite. Thus, $\mathbf{1}$ can serve as a "naked-eye" probe for sulfite. Further, the recognition mechanism of probe $\mathbf{1}$ for sulfite was confirmed using nuclear magnetic resonance and electrospray ionization mass spectrometry. Also, the preliminary practical application demonstrated that our proposed probe provided a promising method for the determination of sulfite.
\end{abstract}

Keywords Colorimetric probe, ratiometric fluorescent probe, sulfite, hydroxynaphthalimide, levulinate moiety, large emission shift

(Received December 11, 2013; Accepted February 14, 2014; Published May 10, 2014)

\section{Introduction}

Sulfites as preservatives, anti-oxidants, and bacteriostatic agents are commonly added to the various food and beverages. ${ }^{1-3}$ However, it has been proved that an excessive intake of sulfites can be dangerous to humans. For example, sulfites can cause the asthmatic and allergic symptoms at higher concentrations, ${ }^{4,5}$ In addition, the Joint FAO/WHO Expert Committee on Food Additives has stated that an acceptable daily intake should be lower than $0.7 \mathrm{mg} / \mathrm{kg}$ of the body weight. ${ }^{6}$ Thus, the quantitative detection of sulfite is of growing importance in food safety systems.

Untill now, many analytical methods, including electrochemistry, ${ }^{1,7}$ chromatography, ${ }^{8,9}$ absorption, ${ }^{2,5,10,11}$ and fluorescence spectroscopy methods, ${ }^{12-19}$ have been developed to detect sulfite quantitatively. Among the above-mentioned methods, fluorescent probes are widely developed due to their high sensitivity, operational simplicity, and bioimaging analysis..$^{20,21}$ For example, Chang et al. reported a pioneering fluorescent probe employing the levulinate moiety as a recognition receptor for the detection of sulfite. ${ }^{16}$ This strategy has been extensively adopted to design other indicators for sulfite. ${ }^{12,17}$ As another example, Zeng and $\mathrm{Wu}$ et al. developed an aldehyde-based fluorescent turn-on probe for sulfite. ${ }^{3}$ Very recently, Guo et al. published a novel fluorescent probe for the detection of bisulfite and sulfite employing the Michael addition reaction strategy. ${ }^{14}$ Despite advances in the development of fluorescent probes for sulfite, most reported examples respond

† To whom correspondence should be addressed.

E-mail: zhangxl@bit.edu.cn to sulfite along with changes only in the fluorescence intensity, which are prone to be disturbed in quantitative detection by many factors, such as variabilities in the excitation and emission efficiency, the sample environments, and the probe distribution. ${ }^{22,23}$ In contrast, ratiometric fluorescent probes can eliminate most, or all, ambiguities by the self-calibration of two emission bands. ${ }^{22,24}$ Additionally, the newly developed ratiometric fluorescent probe should exhibit a large emission wavelength shift $(>80 \mathrm{~nm})$ for practical use in ratiometric measurements. ${ }^{25-27}$ However, to date, ratiometric fluorescent probes with a large emission shift for sulfite have been rather rare. ${ }^{12-14}$ In addition, the colorimetric technique possesses a great advantage over other analytical methods because it has the capability to detect sulfite by the naked-eye, without the aid of any advanced instruments. ${ }^{28-34}$ Thus, novel colorimetric and ratiometric fluorescent probes for sulfite with a large emission shift have become our target.

In previous work, we successfully developed a ratiometric fluorescent probe based on the 4-hydroxynaphthalimide fluorophore. ${ }^{35}$ In connection with our continuing research, we herein describe the design and synthesis of a simple 4-hydroxynaphthalimide-derived ratiometric fluorescent probe (Scheme 1, 1) employing the levulinate moiety as a recognition receptor for the detection of sulfite. Probe $\mathbf{1}$ possesses a compromised internal charge-transfer (ICT) structure due to the opposite electron-withdrawing carbonyl group of the levulinate moiety. The sulfite-mediated cleavage of the levulinate moiety releases a long-wavelength absorption and fluorescence of 4-hydroxy-1,8-naphthalimide, owing to the stronger electrondonor ability of oxygen anions. The reaction mechanism of probe $\mathbf{1}$ and sulfite is shown in Scheme 2. Thus, a colorimetric and ratiometric fluorescent probe for sulfite with a large 


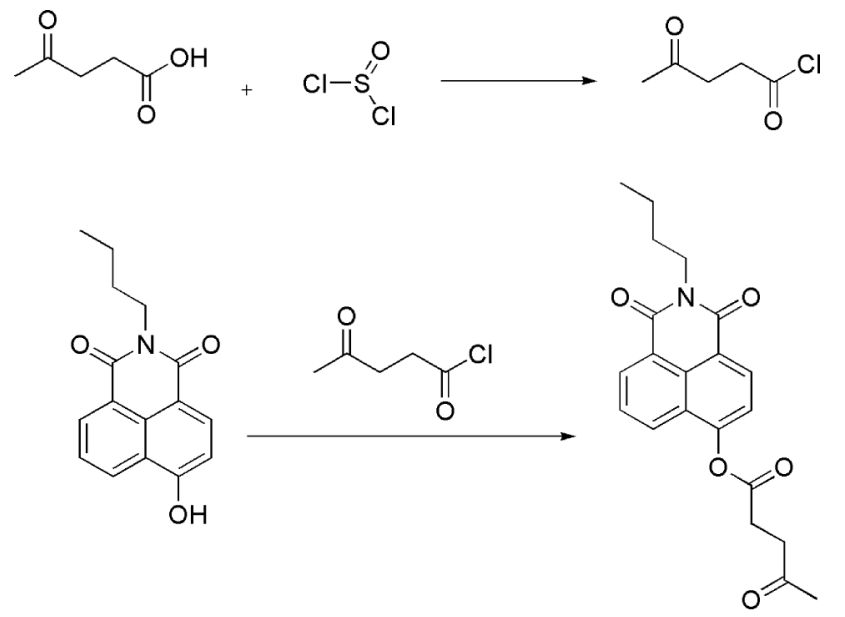

Probe 1

Scheme 1 The synthesis of probe $\mathbf{1}$.

emission shift could be achieved.

\section{Experimental}

\section{Materials and instrumentations}

4-Hydroxy-1,8-naphthalimide was prepared according our previous work. ${ }^{35}$ All other chemicals used in this paper were obtained from commercial suppliers, and used without further purification. Silica gel (200-300 mesh, Qingdao Haiyang Chemical Co.) was used for column chromatography. ${ }^{1} \mathrm{H}-\mathrm{NMR}$ was recorded on a Bruker AV-400 spectrometer with chemical shifts reported as ppm (in $\mathrm{CDCl}_{3}$ or DMSO- $d_{6}$; TMS as an internal standard). Electrospray ionization (ESI) mass spectra were measured with an LC-MS 2010A (Shimadzu) instrument. Absorption spectra were recorded on a UV-3101PC spectrophotometer. Fluorescence emission spectra were measured on a Perkin-Elmer Model LS-55. All pH measurements were made with a Sartorius basic pH-meter, PB-10.

\section{Synthesis of probe 1}

Levulinic acid $(1.1612 \mathrm{~g}, 10 \mathrm{mmol})$ was dissolved in $15 \mathrm{~mL}$ of anhydrous dichloromethane. Then, thionyl chloride $(1.1897 \mathrm{~g}, 10 \mathrm{mmol})$ was added to this solution while stirring under a nitrogen atmosphere. After the mixture was refluxed for $6 \mathrm{~h}$, the resulting mixture was cooled to room temperature. A solution of 4-hydroxy-1,8-naphthalimide $(664.6 \mathrm{mg}, 2 \mathrm{mmol})$ in $20 \mathrm{~mL}$ of $\mathrm{CH}_{3} \mathrm{CN}$ was added to the above resulting mixture, and subsequently triethylamine $(1.0119 \mathrm{~g}, 10 \mathrm{mmol})$ was added. Then, the resulting mixture was stirred at room temperature for $18 \mathrm{~h}$. After removing solvent, the residues were purified by silica-gel column chromatography using dichloromethane as an eluent to afford a pure product. ${ }^{1} \mathrm{H}-\mathrm{NMR}\left(400 \mathrm{MHz}, \mathrm{CDCl}_{3}\right) \delta$ $\left({ }^{*} 10^{-6}\right): 0.974(\mathrm{t}, J=7.2 \mathrm{~Hz}, 3 \mathrm{H}), 1.417-1.492(\mathrm{~m}, 2 \mathrm{H})$, $1.671-1.747(\mathrm{~m}, 2 \mathrm{H}), 1.822(\mathrm{~s}, 3 \mathrm{H}), 2.467-2.524(\mathrm{~m}, 1 \mathrm{H})$, $2.691-2.758(\mathrm{~m}, 1 \mathrm{H}), 2.817-2.878(\mathrm{~m}, 1 \mathrm{H}), 2.914-2.982(\mathrm{~m}$, $1 \mathrm{H}), 4.172(\mathrm{t}, J=7.6 \mathrm{~Hz}, 2 \mathrm{H}), 7.698(\mathrm{~d}, J=8.0 \mathrm{~Hz}, 1 \mathrm{H}), 7.734$ (t, $J=7.8 \mathrm{~Hz}, 1 \mathrm{H}), 8.402(\mathrm{~d}, J=8.4 \mathrm{~Hz}, 1 \mathrm{H}), 8.545$ (d, $J=8.4 \mathrm{~Hz}, 1 \mathrm{H}), 8.614(\mathrm{~d}, J=7.2 \mathrm{~Hz}, 1 \mathrm{H})$. ESI-MS calcd. for $\mathrm{C}_{21} \mathrm{H}_{22} \mathrm{NO}_{5}[\mathrm{M}+\mathrm{H}]^{+} 368$, found 368 .

$3 \mathrm{H}), \quad 1.30-1.39(\mathrm{~m}, 2 \mathrm{H}), \quad 1.56-1.64(\mathrm{~m}, 2 \mathrm{H}), 4.03 \quad(\mathrm{t}$, $J=7.4 \mathrm{~Hz}, 2 \mathrm{H}), 7.16(\mathrm{~d}, J=8.0 \mathrm{~Hz}, 1 \mathrm{H}), 7.77(\mathrm{t}, J=7.8 \mathrm{~Hz}$, $1 \mathrm{H}), 8.36(\mathrm{~d}, J=8.4 \mathrm{~Hz}, 1 \mathrm{H}), 8.48(\mathrm{~d}, J=7.6 \mathrm{~Hz}, 1 \mathrm{H}), 8.54(\mathrm{~d}$, $J=8.4 \mathrm{~Hz}, 1 \mathrm{H}), 11.85(\mathrm{~s}, 1 \mathrm{H})$. ESI-MS calcd. for $\mathrm{C}_{16} \mathrm{H}_{14} \mathrm{NO}_{3}$ $[\mathrm{M}-\mathrm{H}]^{-}$268, found 268 .

\section{Calculation of the detection limit}

Referring to a previous paper, ${ }^{24}$ the detection limit was calculated based on fluorescence titration. In the absence of sulfite, the fluorescence emission spectrum of probe $\mathbf{1}$ was measured five times, and the standard deviation of a blank measurement was achieved. To gain the slope, the ratio of the fluorescence intensity at $441 \mathrm{~nm}$ to the fluorescence intensity at $544 \mathrm{~nm}\left(F_{441} / F_{544}\right)$ was plotted as a concentration of sulfite. Thus, the detection limit was calculated by the following equation: detection limit $=3 \sigma / k$, where $\sigma$ is the standard deviation of the blank measurement, and $k$ the slope between the fluorescence intensity ratio versus the sulfite concentration.

\section{Results and Discussion}

\section{Characteristic spectrum}

Our previous investigations have shown that an appropriate balance between the hydrophilicity and the lipophilicity of the indicator is beneficial to the cell permeability and intracellular imaging. ${ }^{23,24}$ Thus, the spectral responses of probe $\mathbf{1}(5 \mu \mathrm{M})$ toward sulfite were investigated in an ethanol and water (3:7, $\mathrm{v} / \mathrm{v})$ mixed solution.

The solution of free probe $\mathbf{1}$ shows one major absorption peak at around $350 \mathrm{~nm}$ and a fluorescence emission peak at around $441 \mathrm{~nm}$. When sulfite $(500 \mu \mathrm{M})$ was added to the solution of probe 1 , the maximum absorption peak showed an about $100 \mathrm{~nm}$ red shift; also, the color of the solution turned from colorless to yellow, and the maximum emission peak underwent a red shift to $544 \mathrm{~nm}$ (Fig. 1). Compound 1 can serve as a "naked-eye" probe for sulfite. The remarkable changes of the absorption and the fluorescence spectra might be attributed to the cleavage of the opposite electron-withdrawing carbonyl group of the levulinate moiety and the coinstantaneous production of a stronger electron-push capacity of the oxygen anion. These spectra of the reaction solution are in good agreement with those of 4-hydroxy-1,8-naphthalimide, reported by us. ${ }^{35}$ The results implied that the cleavage of levulinate moiety was induced by sulfite.

The propyne-caged hydroxynaphthalimide indicator discussed in our previous paper ${ }^{35}$ can detect palladium species by virtue of a palladium-catalyzed depropargylation reaction. ${ }^{36}$ It thus cannot monitor sulfite, because sulfite cannot catalyze the depropargylation reaction. Similarly, our proposed indicator presented in this paper is a levulinate-caged hydroxynaphthalimide dye. It can detect sulfite owing to a sulfite-mediated cleavage of the levulinate moiety. ${ }^{12,16,17}$ Thus, it cannot detect palladium species, because palladium species cannot catalyze the cleavage of the levulinate moiety reaction. To further confirm the interaction mechanism of $\mathbf{1}$ with sulfite, the reaction of probe $\mathbf{1}$ with sulfite was conducted under the same conditions as described above. The green fluorescent reaction product was obtained and characterized to be compound 2 by ${ }^{1} \mathrm{H}-\mathrm{NMR}$ and ESI-MS. Therefore, combined with the previous conclusions by other groups, ${ }^{12,16,17}$ a possible mechanism was proposed, as shown in Scheme 2.

\section{Effects of the reaction time on sensing sulfite}

The response time is a fundamental parameter for most 

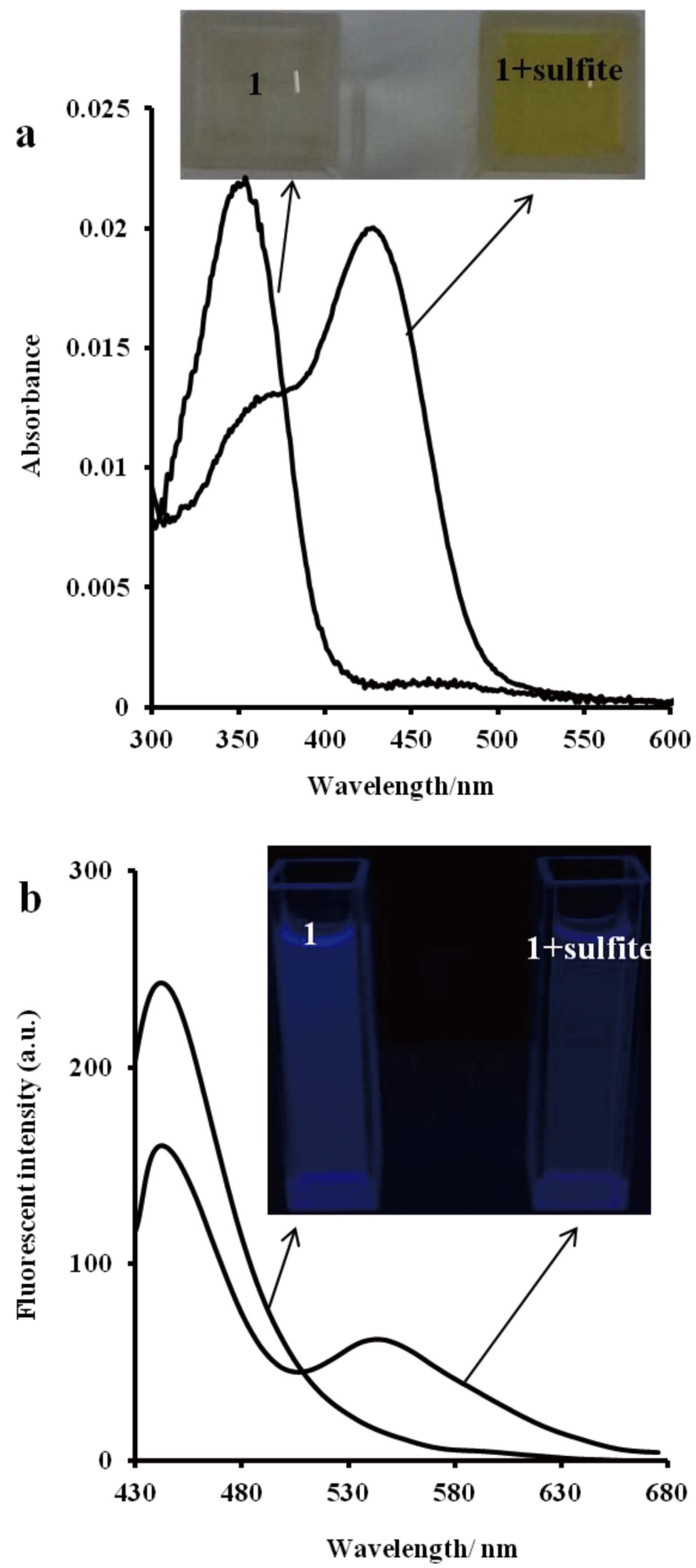

Fig. 1 (a) Absorption responses of probe $1(5 \mu \mathrm{M})$ toward sulfite $(500 \mu \mathrm{M})$ in a mixture of ethanol and water $(3: 7, \mathrm{v} / \mathrm{v})$ solution. Inset: the color changes of probe $\mathbf{1}(25 \mu \mathrm{M})$ in the absence and presence of sulfite. (b) Fluorescence responses $\left(\lambda_{\mathrm{ex}}=380 \mathrm{~nm}\right)$ of probe $1(5 \mu \mathrm{M})$ toward sulfite $(500 \mu \mathrm{M})$ in a mixed ethanol and water $(3: 7, \mathrm{v} / \mathrm{v})$ solution. Inset: the fluorescence color changes of probe $\mathbf{1}(25 \mu \mathrm{M})$ in both the absence and presence of sulfite excited by a UV lamp $\left(\lambda_{\mathrm{ex}}=365 \mathrm{~nm}\right)$.

reaction-based indicators. Thus, the time required for the reaction of probe $\mathbf{1}$ and sulfite at $25^{\circ} \mathrm{C}$ was investigated. As shown in Fig. 2, the fluorescence intensity at $441 \mathrm{~nm}$ decreases with the reaction time, and synchronously the fluorescence intensity at $544 \mathrm{~nm}$ increases with the reaction time. The ratio

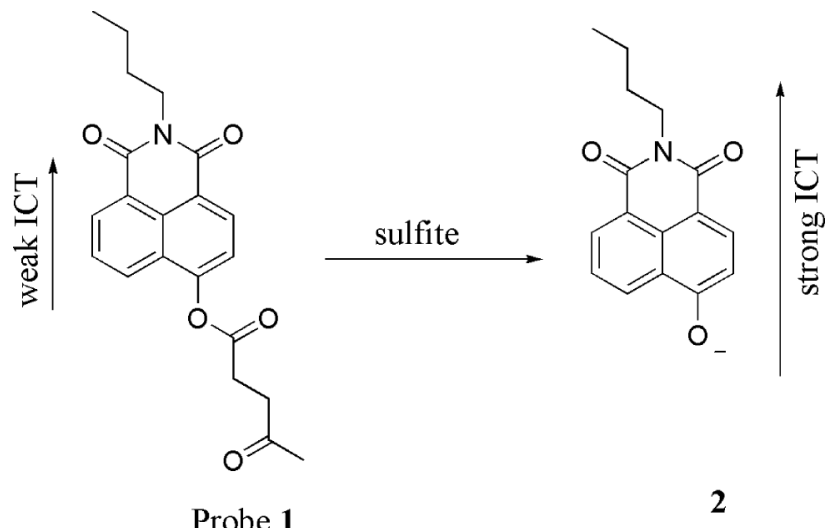

Scheme 2 The proposed recognition mechanism of probe $\mathbf{1}$ and sulfite.

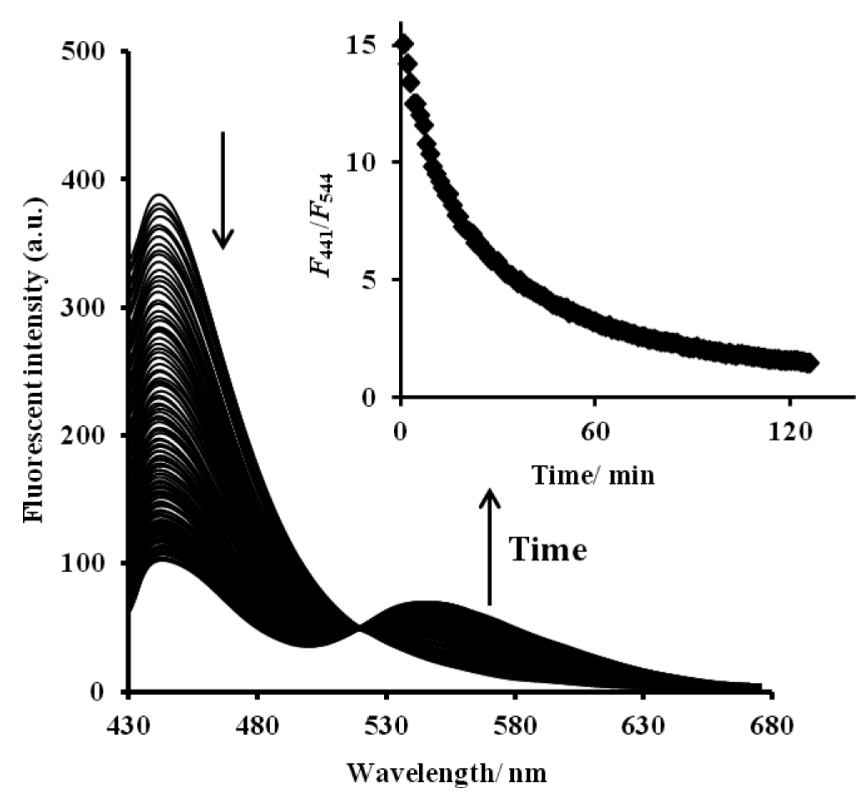

Fig. 2 Fluorescence spectra $\left(\lambda_{\mathrm{ex}}=380 \mathrm{~nm}\right)$ of probe $1(5 \mu \mathrm{M})$ after the addition of sulfite $(10 \mathrm{mM})$ over time in a mixed ethanol and water $(3: 7, \mathrm{v} / \mathrm{v})$ solution.

of the fluorescence intensities $\left(F_{441} / F_{544}\right)$ decreases with the reaction time, and then levels off at reaction times greater than about 60 min (accomplish $>70 \%$ within $30 \mathrm{~min}$ ). This result shows that the rate of the reaction of probe $\mathbf{1}$ with sulfite is close to those of reported levulinate-based fluorescent probes. ${ }^{12,16,17}$ That is to say, our proposed probe could provide an appropriate analytical method for the detection of sulfite.

\section{Quantification of sulfite}

The subsequent addition of sulfite to the solution of probe 1 resulted in a gradual decrease of the fluorescence peak centered at around $441 \mathrm{~nm}$, and a progressive increase of the fluorescence peak centered at around $544 \mathrm{~nm}$ (Fig. 3a). In addition, a well-defined isoemission point at $518 \mathrm{~nm}$ was also observed (Fig. 3a), which implicated that a new species came into being. Moreover, there was a good linearity between the fluorescence intensity ratio $\left(F_{441} / F_{544}\right)$ and the concentrations of sulfite in the range of 80 to $300 \mu \mathrm{M}$ with a detection limit of $12 \mu \mathrm{M}$ (Fig. 3b). These results demonstrated that probe 1 could detect sulfite both 

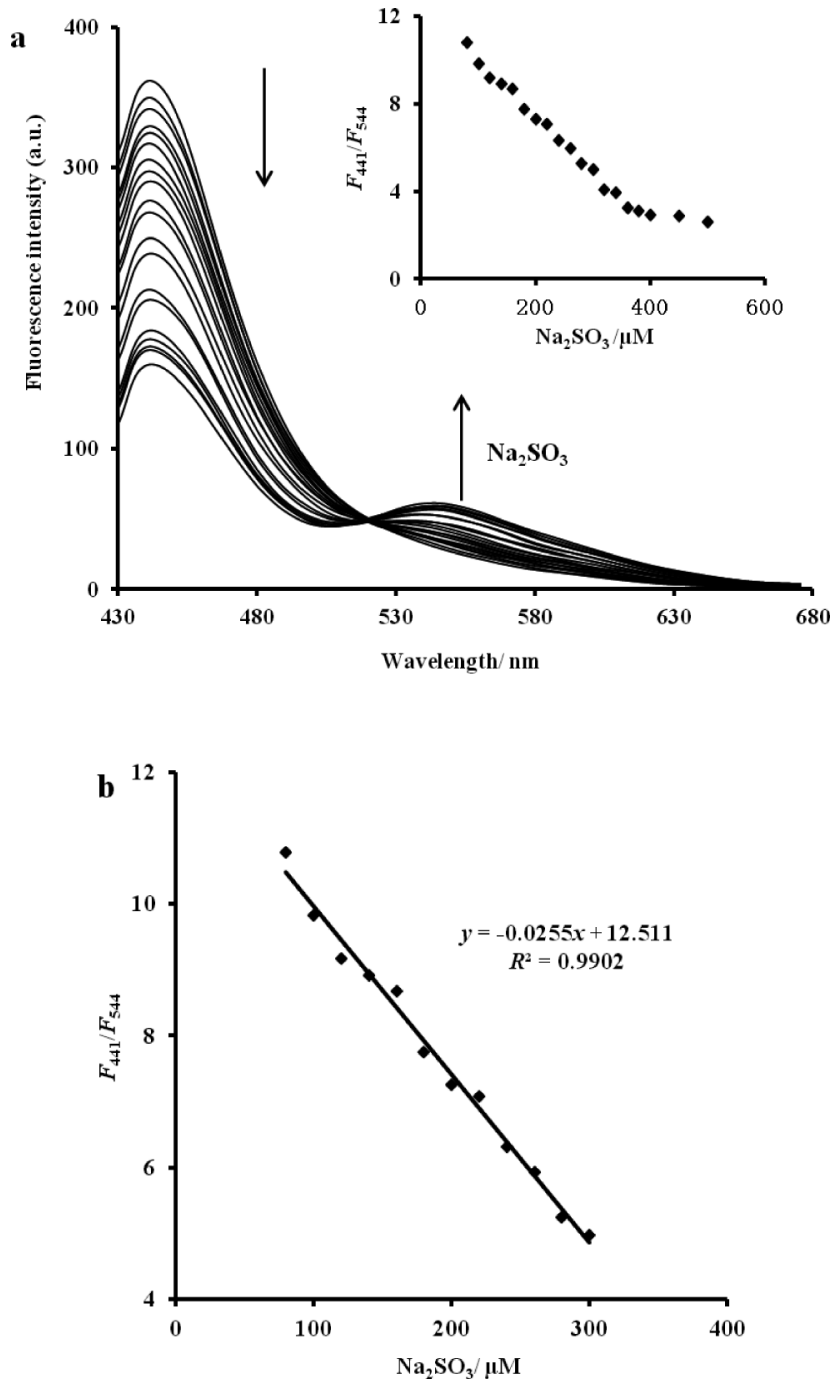

Fig. 3 (a) Fluorescence responses of probe $1(5 \mu \mathrm{M})$ toward different concentrations of sulfite. Inset: the fluorescence intensity ratio $\left(F_{441} / F_{544}\right)$ of probe $1 \mathrm{vs}$. increasing concentrations of sulfite (final concentration: $80,100,120,140,160,180,200,220,240,260,280$, $300,320,340,360,380,400,450$, and $500 \mu \mathrm{M})$. Each spectrum was acquired $60 \mathrm{~min}$ after sulfite addition at $25^{\circ} \mathrm{C}$. (b) Good linearity between the fluorescence intensity ratio $\left(F_{441} / F_{544}\right)$ and the concentrations of sulfite in the range of 80 to $300 \mu \mathrm{M}$.

qualitatively and quantitatively by the ratiometric fluorescence method with excellent sensitivity.

\section{Selectivity to sulfite}

Then, the selectivity of probe $\mathbf{1}$ toward sulfite under the same conditions was evaluated. As expected, nearly no fluorescence intensity changes were observed in the presence of $\mathrm{NO}_{2}{ }^{-}, \mathrm{NO}_{3}{ }^{-}$, $\mathrm{SO}_{4}{ }^{2-}, \mathrm{CO}_{3}{ }^{2-}, \mathrm{SCN}^{-}, \mathrm{S}^{2-}, \mathrm{Br}^{-}, \mathrm{CH}_{3} \mathrm{COO}^{-}, \mathrm{I}^{-}, \mathrm{Cl}^{-}$, and $\mathrm{HSO}_{3}^{-}$ (Fig. 4a). In addition, the effects of the interference of the above-mentioned other anion analytes on monitoring sulfite were investigated (Fig. 4b). These results demonstrated that probe 1 possesses high selectivity toward sulfite when present with other anions.

\section{Application of probe 1 in real water samples}

To further demonstrate the practical ability of probe $\mathbf{1}$ to detect sulfite, we carried out experiments in contaminated real water samples. To evaluate the universality of probe $\mathbf{1}$ for the
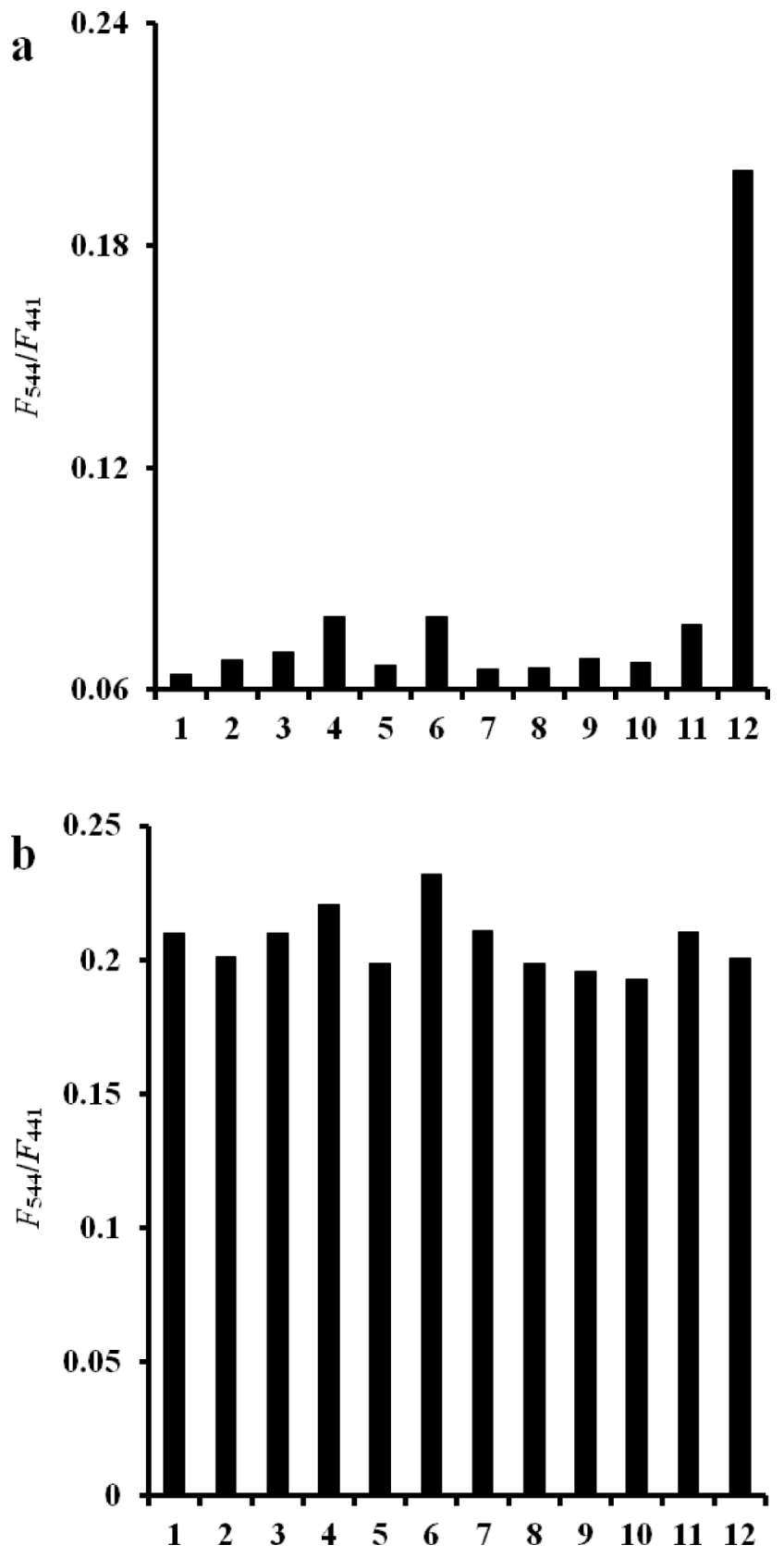

Fig. 4 (a) Fluorescence responses of probe $\mathbf{1}(5 \mu \mathrm{M})$ toward various anions $\left(1, \mathrm{NO}_{2}^{-} ; 2, \mathrm{NO}_{3}^{--} ; 3, \mathrm{SO}_{4}^{2-} ; 4, \mathrm{CO}_{3}^{2-} ; 5, \mathrm{SCN}^{-} ; 6, \mathrm{~S}_{2}^{-} ; 7, \mathrm{Br}^{-} ; 8\right.$, $\left.\mathrm{CH}_{3} \mathrm{COO}^{-} ; 9, \mathrm{I}^{-} ; 10, \mathrm{Cl}^{-} ; 11, \mathrm{HSO}_{3}^{--} ; 12, \mathrm{SO}_{3}^{2-} ; 300 \mu \mathrm{M}\right)$ in a mixed ethanol and water $(3: 7, \mathrm{v} / \mathrm{v})$ solution. All data represent the fluorescence intensity ratio $\left(F_{544} / F_{441}\right)$ of probe $1\left(\lambda_{\text {ex }}=380 \mathrm{~nm}\right)$. (b) Fluorescence responses of probe $\mathbf{1}(5 \mu \mathrm{M})$ toward sulfite $(300 \mu \mathrm{M})$ in the presence of other anions $\left(1, \mathrm{NO}_{2}^{-} ; 2, \mathrm{NO}_{3}{ }^{-} ; 3, \mathrm{SO}_{4}^{2-} ; 4, \mathrm{CO}_{3}{ }^{2-} ; 5\right.$, $\mathrm{SCN}^{-} ; 6, \mathrm{~S}^{2-} ; 7, \mathrm{Br}^{-} ; 8, \mathrm{CH}_{3} \mathrm{COO}^{-} ; 9, \mathrm{I}^{-} ; 10, \mathrm{Cl}^{-} ; 11, \mathrm{HSO}_{3}^{--} ; 12$, none; $300 \mu \mathrm{M})$ under a mixed ethanol and water $(3: 7, \mathrm{v} / \mathrm{v})$ solution. All data represent the fluorescence intensity ratio $\left(F_{544} / F_{441}\right)$ of probe 1 $\left(\lambda_{\mathrm{ex}}=380 \mathrm{~nm}\right)$.

determination of sulfite, three different water samples were chosen. Tap water sampies 1, 2 and 3 were taken from three different headwaters, which might have contained different amounts of biologically important mineral substances and anions. In brief, some known concentrations of sulfite were added to the real water samples, and then the quantification of sulfite was implemented through the above-mentioned analytical 
Table 1 Results for the determination of sulfite in contaminated real water samples

\begin{tabular}{crccc}
\hline $\begin{array}{c}\text { Real water } \\
\text { sample }\end{array}$ & Added sulfite/ $\mu \mathrm{M}$ & Found/ $\mu \mathrm{M}$ & Recovery, $\%$ & $\begin{array}{c}\text { RSD, \% } \\
(n=3)\end{array}$ \\
\hline Tap water 1 & 0 & - & - & - \\
& 150 & 144.6 & 96.4 & 8.79 \\
Tap water 2 & 200 & 197.4 & 98.7 & 7.64 \\
& 0 & - & - & - \\
Tap water 3 & 150 & 157.9 & 105.27 & 9.18 \\
& 200 & 206.2 & 103.1 & 6.14 \\
& 150 & - & - & - \\
& 200 & 142.9 & 95.27 & 5.64 \\
\hline
\end{tabular}

Analytical conditions: a mixture of ethanol and water $(3: 7, \mathrm{v} / \mathrm{v})$ solution.

method. Adequate recovery and acceptable repeatability were obtained, as can be seen in Table 1. Therefore, our proposed method is an excellent choice for the measurement of sulfite.

\section{Conclusions}

In summary, we have presented the design, synthesis and properties of a 4-hydroxynaphthalimide-based colorimetric and ratiometric fluorescent probe $\mathbf{1}$ employing a levulinate moiety as a highly selective recognition receptor for sulfite. Probe $\mathbf{1}$ showed a $100 \mathrm{~nm}$ red-shifted absorption spectrum accompanying color changes from colorless to yellow, and thus can serve as a "naked-eye" probe for sulfite. Additionally, probe 1 exhibited a large $(103 \mathrm{~nm})$ red-shifted fluorescence emission upon the addition of sulfite, and could quantitatively detect sulfite by the ratiometric fluorescence spectroscopy method with high sensitivity. Further, the application of probe $\mathbf{1}$ in real water samples demonstrated that our proposed probe would offer an excellent assay for the determination of sulfite in an aqueous environment.

\section{Acknowledgements}

We gratefully acknowledge financial support from the National Nature Science Foundation of China (Nos. 21275018 and 21203008), Research Fund for the Doctoral Program of Higher Education of China (RFDP) (No. 20121101110049) and the 111 Project (B07012) for financial support.

\section{References}

1. A. Isaac, A. J. Wain, R. G. Compton, C. Livingstone, and J. Davis, Analyst, 2005, 130, 1343.

2. J. Zhang, X. W. Xu, and X. R. Yang, Analyst, 2012, 137, 3437.

3. C. M. Yu, M. Luo, F. Zeng, and S. Z. Wu, Anal. Methods, 2012, 4, 2638.

4. K. R. B. Silva, I. M. Raimundo, I. F. Gimenez, and O. L. Alves, J. Agric. Food Chem., 2006, 54, 8697.

5. D. Lowinsohn and M. Bertotti, Food Addit. Contam., 2001, $18,773$.

6. M. Koch, R. Köppen, D. Siegel, A. Witt, and I. Nehls, J.
Agric. Food Chem., 2010, 58, 9463.

7. U. T. Yilmaz and G. Somer, Anal. Chim. Acta, 2007, 603, 30.

8. S. Fäldt, B. Karlberg, and W. Frenzel, Fresenius' J. Anal. Chem., 2001, 371, 425.

9. J. Rethmeier, A. Rabenstein, M. Langer, and U. Fischer, J. Chromatogr. A, 1997, 760, 295.

10. J. Zhang, Y. Yuan, X. L. Wang, and X. R. Yang, Anal. Methods, 2012, 4, 1616.

11. M. Zhang, Y. Q. Liu, and B. C. Ye, Analyst, 2011, 136, 4558.

12. S. Chen, P. Hou, J. X. Wang, and X. Z. Song, RSC Advances, 2012, 2, 10869.

13. M. Y. Wu, T. He, K. Li, M. B. Wu, Z. Huang, and X. Q. Yu, Analyst, 2013, 138, 3018.

14. Y. Q. Sun, J. Liu, J. Y. Zhang, T. Yang, and W. Guo, Chem. Commun., 2013, 49, 2637.

15. H. Tian, J. Qian, Q. Sun, H. Bai, and W. Zhang, Anal. Chim. Acta, 2013, 788, 165.

16. M. G. Choi, J. Hwang, S. Eor, and S. K. Chang, Org. Lett., 2010, 12, 5624.

17. X. F. Gu, C. H. Liu, Y. C. Zhu, and Y. Z. Zhu, J. Agric. Food Chem., 2011, 59, 11935.

18. Y. Sun, C. Zhong, R. Gong, H. Mu, and E. Fu, J. Org. Chem., 2009, 74, 7943.

19. H. F. Xie, F. Zeng, C. M. Yu, and S. Z. Wu, Polym. Chem., 2013, 4, 5416.

20. L. Yang, Q. Zhao, W. Feng, and F. Li, Chem. Rev., 2013, 113, 192.

21. J. Du, M. Hu, J. Fan, and X. Peng, Chem. Soc. Rev., 2012, $41,4511$.

22. J. L. Fan, M. M. Hu, P. Zhan, and X. J. Peng, Chem. Soc. Rev., 2013, 42, 29.

23. B. C. Zhu, F. Yuan, R. X. Li, Y. M. Li, Q. Wei, Z. M. Ma, B. Du, and X. L. Zhang, Chem. Commun., 2011, 47, 7098.

24. B. C. Zhu, X. L. Zhang, Y. M. Li, P. F. Wang, H. Y. Zhang, and X. Q. Zhuang, Chem. Commun., 2010, 46, 5710.

25. W. Lin, L. Long, L. Yuan, Z. Cao, B. Chen, and W. Tan, Org. Lett., 2008, 10, 5577.

26. W. Xuan, C. Chen, Y. Cao, W. He, W. Jiang, K. Liu, and W. Wang, Chem. Commun., 2012, 48, 7292.

27. B. C. Zhu, H. L. Jiang, B. P. Guo, C. X. Shao, H. F. Wu, B. $\mathrm{Du}$, and Q. Wei, Sens. Actuators, B, 2013, 186, 681.

28. F. Azizian, A. J. Field, B. M. Heron, and C. Kilner, Chem. Commun., 2012, 48, 750 .

29. S. Aiken, D. Clayton, C. D. Gabbutt, B. M. Heron, and S. B. Kolla, Dyes Pigm., 2013, 97, 118.

30. C. D. Gabbutt, B. M. Heron, C. Kilner, and S. B. Kolla, Dyes Pigm., 2012, 94, 175.

31. X. M. Huang, Z. Q. Guo, W. H. Zhu, Y. S. Xie, and H. Tian, Chem. Commun., 2008, 5143.

32. W. H. Zhu, X. M. Huang, Z. Q. Guo, X. M. Wu, H. H. Yu, and H. Tian, Chem. Commun., 2012, 48, 1784.

33. H. N. Kim, Z. Q. Guo, W. H. Zhu, J. Yoon, and H. Tian, Chem. Soc. Rev., 2011, 40, 79.

34. C. D. Gabbutt, L. V. Gibbons, B. M. Heron, and S. B. Kolla, Dyes Pigm., 2012, 92, 995.

35. B. C. Zhu, C. C. Gao, Y. Z. Zhao, C. Y. Liu, Y. M. Li, Q. Wei, Z. M. Ma, B. Du, and X. L. Zhang, Chem. Commun., 2011, 47, 8656.

36. M. Pal, K. Parasuraman, and K. R. Yeleswarapu, Org. Lett., 2003, 5, 349. 